\title{
POLÍTICAS DE CURRÍCULO, FORMAÇÃO E FETICHE: a propósito de príncipes, simplificações e idolatrias
}

\author{
Roberto Sidnei Macedo \\ Universidade Federal da Bahia - UFBA, Brasil
}

\begin{abstract}
Resumo
O artigo em pauta trata de como políticas de currículo e formação utilizam-se de concepções e referências, apresentando-as como compreensões e orientações deônticas, configuradas, não raro, como fetiches. A partir de uma perspectiva crítico-cultural, o presente escrito compreende os processos de fetichização a partir de espaçostempos nos quais a produção de fetiches se realiza de forma culturalmente plural e generativa. Na sua especificidade, opta em compreender a fetichização nas/das políticas de currículo e formação a partir de uma abordagem crítica aos movimentos de simplificação totalizante recorrentes nessas políticas, com significativas e preocupantes ressonâncias essencialistas nos meios educacionais. Nesses termos, os argumentos produzidos direcionam-se no sentido de analisar como os fetiches presentes no texto curricular-normativo se configuram como "idolatrias" (PINAR, 2014). Cultivam, ademais e de forma intensa, a regulação como um dos seus centros de interesse. No movimento analítico ampliado desse artigo, inspirado em Silva (1999a), produz-se um questionamento que se amplia, qual seja: nos contextos das políticas curriculares do presente, o currículo como produção cultural pensadapraticada emerge de forma realçada como um fetiche?
\end{abstract}

Palavras-chave: Currículo; Políticas de currículo; Formação; Fetiche.

\begin{abstract}
The article in question discusses how curriculum and training policies use conceptions and references, presenting them as deontic understanding and orientation, often characterized as fetishes. From a critical-cultural perspective, this work comprehends the processes of fetishization from a space-time in which the production of fetishes occurs in a culturally plural and generative manner. In its specificity, it opts to understand the fetishization in/of curriculum policies and training from a critical approach towards totalizing simplification movements recurrent in these policies, with significant and worrying existentialist resonances in the field of education. In these terms, the produced arguments are directed at analyzing how the fetishes present in the curricular normative documents are characterized as "idolatry" (PINAR, 2014). Moreover, they intensely highlight regulation as one of their centers of interest. In this article's extended analytical movement, inspired by Silva (1999a), a questioning is made which is extended, i.e., in the context of the current curricular policies, does the curriculum as a thought/practiced cultural production appear in a highlighted way as a fetish?
\end{abstract}

Keywords: Curriculum; Curriculum policies; Training; Fetish. 


\section{Introdução}

Há algum tempo nossa disponibilização crítica diante das simplificações totalizantes e dos essencialismos das denominadas políticas de currículo e formação, esforça-se em demonstrar como essas políticas escolhem de forma deôntica uma determinada concepção, referência ou mesmo "modelo" de currículo para pautar suas orientações e recomendações, em geral com claras intenções exterodeterminantes. Tomemos como um exemplo dos últimos anos, para começar a aquecer os nossos argumentos, o já costumeiro fetiche pelas competências, propostas para compor organizadores curriculares de políticas e práticas formacionais. Esse é um tema sobre o qual, a partir dos nossos interesses de texto, argumentaremos de forma ampliada mais adiante, em face da sua importância para os propósitos deste artigo.

Há algum tempo também, estudamos de forma aguçada a partir das nossas miradas críticas, a dinâmica das disputas no campo curricular-formacional, seus jogos e seus interesses políticos. Para nós, essa é uma pauta inarredável, ao mesmo tempo em que cultivamos sempre e necessariamente, revisitas à crítica, ou seja, ao trabalho incansável de exercício da intercriticidade ${ }^{1}$ (ATLAN, 1993), viés da produção curricular etnoconstitutiva do Grupo de Pesquisa com o qual trabalhamos. Ao lado dessa nossa disponibilidade, habitava-nos uma indagação que, de alguma forma, moveu as pautas que foram configurando e vislumbrando esse nosso escrito aqui publicado, isto é: que outras dinâmicas e implicações curriculantes $^{2}$ poderiam estar acontecendo vinculadas às simplificações ${ }^{3}$ totalizantes $^{4}$ e seus costumeiros instrumentalismos, tomando como referência as atuais políticas de currículo e formação, seus interesses e suas proposições? Nesse sentido, temos como pauta de compreensão e como exemplo a emergência dos Parâmetros Curriculares Nacionais, e as diversas diretrizes que tomam o currículo como centralidade, a BNCC (BRASIL, 2018a) e a BNC-Formação (BRASIL, 2019).

Não raro, o argumento curricular nesses casos reduz suas pautas a determinados abstracionismos conceituais ou metodológicos ou mesmo passa a tocar em quase tudo que acontece nas instituições educacionais como uma atualização do gosto esgarçado por uma certa regulação totalizante. Texto curricular como fetiche? Segundo Silva (1999a), provavelmente. É preciso realçar ainda, que em alguns desses documentos curriculares não encontramos quase nada dos argumentos do campo curricular, a exemplo e de forma marcante, o que faz a Resolução 02/2019 do CNE, a denominada BNC-Formação, que trata das (in)tensamente contestadas Diretrizes Curriculares para Formação Inicial e Continuada em Nível Superior de Profissionais do Magistério da Educação Básica, pautada na BNCC e suas orientações.

Nesse próprio movimento encontramos o oposto, ou seja, a ambígua redução pedagógica da política de currículo e formação a determinados modelos ou organizadores curriculares, não raro apresentados e propostos aos professores(as), entre outros profissionais da educação, sem explicitações e/ou justificativas. De forma simplificada o documento concebido tornase uma produção deôntica a ser pretensamente "aplicada" e, a partir da qual, referenciais e práticas devem ser "adaptados" ou "adequados". Assim, fomos descortinando nessa 
itinerância questionante uma certa motivação aguçada em compreender, por exemplo, a idolatria das simplificações totalizantes e seus diversos essencialismos presentes em políticas de currículo nacionais, estaduais e municipais. Vejamos, a esse respeito, as pertinentes reflexões de Pinar (2014) sobre as avaliações que envolvem direta ou indiretamente políticas de currículo, entre outras práticas curriculares:

A relação da sociedade com os testes padronizados na educação e com as provas em geral tornou-se uma espécie de idolatria (grifo nosso), no sentido protestante de que o teste pode atuar como substituto para a experiência, para a revelação, a percepção e a compreensão. A experiência do teste substitui a experiência da compreensão. (PINAR, 2014, p. 95)

Em meio a esses exercícios críticos, observações sob a forma de inquietos insights passaram a habitar nossas aulas e seminários envolvendo a formação de professores, produzindo narrativas como: "prestemos atenção a esses fetiches pelo modelo curricular único, pelo método e pela regulação, que em geral, aparecem como modos encantatórios e simplificados de produzir políticas de currículo e formação"; "vejamos como muito do que se anuncia como currículo pouco corresponde às discussões do campo curricular"; "o currículo torna-se no momento um fetiche?". Essas narrativas passaram a configurar lapsos de compreensão ainda pouco elucidativos sobre o fetiche como uma questão de políticas de currículo. Assim, permaneceram por algum tempo como fortuitas fustigações e provocações ao nosso pensar sobre o texto curricular-normativo. Entretanto, mais recentemente, em meio ao acirramento das simplificações totalizantes e seus essencialismos nessa especificidade das práticas curriculares e formacionais, o nosso interesse pela fetichização nas políticas de currículo e formação foi tomando densidade e forma. Numa das revisitas à obra Currículo: campo, conceito e pesquisa (MACEDO, 2021) na qual, simbolicamente, a cada capítulo o príncipe - o currículo - renova sua arte de poder e sedução, uma referência a metáfora da obra de Maquiavel, $O$ príncipe (2018), percebemos argumentos importantes que vem nos aproximando mais ainda da perspectiva de que no currículo como configurador de política de formação emanam fetiches principescos.

Nesse movimento encontramo-nos interessados mais uma vez numa conversa que tivemos com o professor Tomaz Tadeu da Silva a partir da leitura da sua obra $O$ Currículo como Fetiche: a poética e a política do texto curricular (1999a). Daí adveio outra indagação mais ampliada e de significativo teor provocativo: de fato o currículo como política tornouse um fetiche em si? Começamos então a garimpar possibilidades compreensivas nesse sentido. "Fechou-se" assim um certo ciclo nascente de insights e de interesses em caminhar ao encontro de uma certa dilatação elucidativa sobre nossos questionamentos referentes às simplificações totalizantes e aos essencialismos das questões e pautas curricularesformacionais. Acabamos compreendendo nesse contexto, ofetiche como um ato de currículo político-generativo (MACEDO, 2013). A partir desse movimento, revisitamos a obra de Silva (1999a), bem como rememoramos a significativa amplitude multirreferencializada com a qual o autor trabalha o fetiche, a fetichização e as suas ressonâncias nas questões do 
currículo, num certo ir vir do seu inquieto e "lúdico" pensamento crítico-cultural, através de um diálogo fecundo com os pensares de Freud e Marx. Começava a configurar-se nesse tempoespaço o nosso interesse pelo fetiche como um analisador ${ }^{5}$ de políticas de currículo e formação. Nesse mesmo veio dialógico, nos inspiramos de forma mobilizada em LéviStrauss, quando falava aos seus estudantes que o fetiche era bom para se pensar culturalmente. A propósito, Silva (1999a, p. 73) nos indaga: "Não seria o fetiche bom também para pensar o currículo e a pedagogia?".

É com esse conjunto de identificações dialógicas quanto ao interesse da crítica cultural pelo fetiche e sobre a fetichização nas políticas curriculares que começamos a mobilizar as nossas perspectivas etnoconstitutivas (MACEDO, 2016) para produzirmos nossas compreensões sobre o fetichização, como produção de atos de currículo no contexto das denominadas políticas curriculares com proposições formacionais. Nesses termos, vamos compreender o fetiche como algo que institui simbolizações, intenções, teorias, etnométodos, instituintes culturais. Configura, a propósito, com-versações que podem ser curriculantes e formacionais, generativas e políticas, porque valoradas, perspectivais, portanto.

\section{Sobre o fetiche}

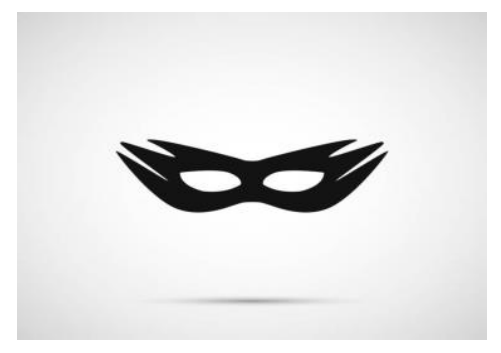

Figura 1: Uma simbolização de fetiche.

Em: https://www.istockphoto.com/vetor/m\%C3\%A1scara-de-vetor-sexo-isolada-no-fundobranco-gm927802892-254496319. Acesso em agosto de 2021.

Faz-se pertinente no processo elucidativo deste nosso escrito, que possamos construir alguns argumentos sobre o movimento etiológico da concepção de fetiche e sua dinâmica de sentidos. Etimologicamente a palavra tem sua política de sentidos marcada pela derivação do português fetisso, que mais tarde evoluiu para feitiço. Percebemos nesse movimento semiótico, certa dinâmica encantatória e mágica que vai se projetando para, em parte, revelarse em algumas culturas e sociedades, como é o caso da forma francesa de apropriação da palavra fétiche. Temos assim derivações como feitiço, fetisso, fétiche, fetiche. Analisando esse acontecer semântico, Silva (1999a, p. 72) nos diz:

No entrechoque dos "encontros" coloniais, são as práticas supostamente mágicas e irracionais do "outro" colonial que passam a merecer a depreciativa designação. 
Finalmente, ao regressar, por assim dizer, ao território europeu, recuperado pela crítica social (Freud, Marx), são certas práticas características da "moderna" sociedade ocidental (sexuais, econômicas, sociais) que, numa inversão da "acusação" original, são vistas como fetichistas (SILVA, 1999a, p. 72).

Há um traço que funda a dinâmica do fetiche e faz-se necessário ressaltar, isto é: a sua inerente ambiguidade. Além de misturar coisa com pessoas, o fetiche pode significar tanto o que encanta, fascina, agrada, quanto o que rejeita, o que causa malefício e necessidade de distanciamento e estranheza. Da perspectiva cultural, o fetiche é generativo e emana (in)tensa valoração, como já dissemos. Nesse sentido é poético, político, moral, estético e transcendental. Mostra-se, esgueira-se, engana, elucida, mobiliza, deixa-se em opacidade, confunde, enebria, seduz, assombra, causa estranheza, atrai, dialoga, faz calar, enfeitiça. É experiencial e acontecimental, porque nele habita o reino intenso e inarredavelmente plural da produção de sentidos.

No importante movimento psicanalítico freudiano o fetichismo é uma perversão. Por conseguinte, uma das versões negativas do seu sentido. Ou seja, um desvio da subjetividade realizado pelo complexo de Édipo e a dinâmica fixional da sexualidade através, por exemplo, da invenção de substitutos de um pênis atribuído a mãe castrada. Surgem assim objetos de desejo substitutos, "parciais", como roupas íntimas, sapato, pé, entre outros objetos de uso e partes do corpo. O fetichismo, assim, é uma perversão, uma deturpação da subjetividade sexual. O fetichista sabe da parcialidade da dinâmica da sua subjetividade sexual, mas se recusa a acreditar nessa condição. Ambiguidade e instabilidade são aqui inseridas na relação com o desejo.

Assim como Freud, como nos aponta Silva (1999a), Marx percorre um caminho similar a partir dos seus argumentos sobre a crítica à mercadoria, quando aborda a questão do fetichismo como negativo na sua dinâmica parcial. Nesse movimento compreensivo, coisas e pessoas não devem ser confundidas. Marx, assim, argumenta Silva (1999a), vai investir na demonstração do fetichismo da mercadoria.

$\mathrm{Na}$ análise marxiana do fetiche da mercadoria, pois, o foco não é, como no fetichismo "original", uma coisa cujo caráter enigmático resulta do esquecimento de que seu poder extraordinário é a criação do próprio fetichista, mas uma abstração cujo caráter enigmático resulta das características do funcionamento do mercado. O que se esquece, o que se esconde, no fetichismo da mercadoria é que o mercado é uma criação humana e que o valor de troca da mercadoria é resultado de trabalho humano. Estão envolvidos, no fetichismo da mercadoria, dois movimentos inversos de transfiguração: uma relação originalmente social, entre pessoas, manifestando-se como relação entre coisas; essa relação entre coisas, por sua vez, apresenta-se como se fosse uma relação entre pessoas, uma relação social. Há uma "coisificação" e uma "personalização" (SILVA, 1999a p. 82).

Numa perspectiva crítica próxima, Benjamin (1994, p. 52) argumenta que "aquilo que fala é o próprio fetiche. [...] A mercadoria retira o mesmo efeito que a droga da multidão 
inebriada e murmurante a seu redor. [...] o mercado que transforma a mercadoria em mercadoria aumenta o seu encanto [...]”. Assim, numa transfiguração, o fetiche do consumo se torna objeto de encanto do fetichista. Dessa forma, no fetichismo da mercadoria assume o lugar da relação entre as pessoas.

No que se refere à crítica cultural de viés pós-estrutural, o fetiche é modo de fazer (SILVA, 1999). Assim, da perspectiva da crítica ao iluminismo, o fetiche na crítica cultural pós-estrutural sai, pois, do escopo de uma visão que o coloca sempre no lugar negativo da perversão, do desvio e da ilusão. A proposta é que a cultura seja também pensada através da fetichização. Que o fetiche seja uma metáfora fecunda, boa para pensar as dinâmicas culturais, evitando um certo viés construcionista que quer desfetichizar o mundo, numa espécie de exercício da crítica epistemológica politicamente correta do fetiche, como se a fetichização não fizesse parte também das ciências sociais e não criasse mundos sociais e culturais como a ciência, por exemplo. Desconfigura-se aqui o purismo acadêmico e científico e seus lugares pretensamente desfetichizados. Nesses termos, todos, todas e todes vivemos experienciando o mundo dos fetiches. Cabe, então, nos questionarmos: Somos exteriores ao fetiche? Os purismos teórico-corporativos não seriam também fetiches?

A partir desse contexto de questionamentos e argumentos, optamos a partir do escopo da Teoria Etnoconstitutiva de Currículo e sua dinâmica intercrítica (MACEDO, 2016; ATLAN, 1993) em pensar o fetiche numa dinâmica ontológica, epistemológica, cultural e política, constituída por etnométodos ${ }^{6}$ culturalmente generativos. Dessa perspectiva etnoconstitutiva, o fetiche é um modo de pensarfazer cotidiano, que sendo constitutivo de realidades, institui sentidos indexicalizados ${ }^{7}$ às dinâmicas culturais do seu contexto de produção. Seus etnométodos, para todos os seus fins práticos, produzem encantos, seduções, assombrações, bem como descritibilidades, inteligibilidades, analisibilidades, reflexibilidades, sistematicidades, implicações e sobreimplicações, como nos inspira, em parte, a etnometodologia de Garfinkel (1976), assim como a Análise Institucional Francesa no que se refere às duas últimas categorias citadas. Assim, a partir da compreensão da Teoria Etnoconstitutiva de Currículo (MACEDO, 2016) fetiche é ato de currículo culturalmente produzido e, como todo ato de currículo, é produção e experiência cultural valorada, perspectival, portanto. 


\section{O fetiche no texto curricular}

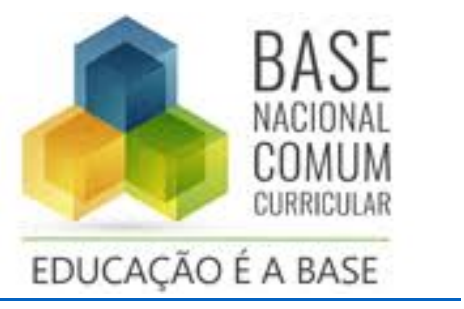

Figura 2 - Logo da BNCC, na qual percebe-se uma apropriação da expressão comumente encontrada nas recomendações de pais e famílias para jovens estudantes sobre a importância da educação como "base para vida". Ao mesmo tempo a composição imagética-verbal joga com o sentido de que a educação e a formação devem fundamentalmente pautar-se na Base Nacional Comum Curricular. Uma das expressões deônticas das suas orientações curriculares e formacionais.

Em: http://basenacionalcomum.mec.gov.br/. Acesso em agosto de 2021

Recorremos mais uma vez ao inquieto pensamento de Silva (1999a) sobre o fetiche, agora mais focado no texto curricular. Para o autor em pauta, é bem melhor que falemos desse assunto fazendo a questão para nós mesmos: "E se o currículo fosse um fetiche?" (SILVA, 1999a, p. 73). Percebe-se com essa proposição que o autor cria uma espécie de abertura para se pensar a complexidade do processo de fetichização.

Por um lado, o conhecimento corporificado no currículo tem sido pensado e tratado tradicionalmente como uma coisa à qual se atribui certos poderes transcendentais, quase extra-humanos. Por outro, a crítica educacional tem denunciado precisamente seu caráter construído, humano, social. O currículo é, pois, um fetiche nos dois sentidos: para os "nativos" que são incapazes de percebêlo como produto de sua própria criação; para os "forasteiros" que, contrariamente, são capazes de perceber o engano em que estão envolvidos os "nativos", denunciados, então, como fetichistas. Uma terceira alternativa [...] consistiria em explorar a ambiguidade do fetiche. Nem a "ingenuidade" dos "nativos", nem a "lucidez" dos "forasteiros" [...] o fetiche se situa exatamente naquela zona obscura em que se encontram, clandestinamente, as coisas propriamente ditas e as "coisas feitas", o humano e o transcendental, a natureza e a cultura, o pré-social e o social" (SILVA, 1999a, p. 73).

Após essas considerações, Silva (1999a, p. 101) continua a nos provocar: "De posse do fetiche - o conhecimento corporificado no currículo - os 'nativos' se sentem seguros, assegurados, protegidos contra a incerteza, a indeterminação e a ansiedade do ato de conhecer". Nesse veio argumentativo a provocação amplia-se: “[...] E se utilizássemos a metáfora do fetiche para analisar e pensar o currículo?" Acrescentamos a partir dos nossos interesses de texto: e se olhássemos a imagem que inicia este tópico do nosso escrito - uma das diversas logos da BNCC - como uma certa fetichização do "Nacional Comum Curricular"? A logo em pauta apropria-se simbolicamente da frase, "Educação é a Base" a 
partir de um jogo viesado de possibilidades vinculadas a um enaltecimento simplificado e totalizante da BNCC, suas orientações e promessas.

Assim, a partir das nossas inspirações etnoconstitutivas, aceitamos essa provocação metafórica e cultural de forma ampliada, articulando-as aos nossos questionamentos e argumento sobre o fetiche das/nas políticas de currículo e formação.

\section{O fetiche nas/das políticas de currículo e formação}

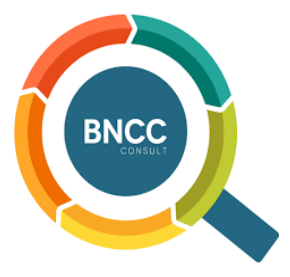

Figura 3 - Logo da Base Nacional Comum Curricular apresentada através de uma lupa estilizada. Aparece nessa produção o intuito de veicular o nível de alcance nacional pretendido e configurado pela propaganda da BNCC e pela BNCC em si, no que se refere aos seus projetos e propostas formacionais.

Em:http://www.consed.org.br/central-de-conteudos/aplicativo-sobre-bncc-alcanca-mais-de-10mil-downloads

Acesso em agosto de 2021.

Há que ressaltar, a partir do nosso contexto de questionamentos e argumentos neste escrito, que o fetiche é curriculante.

Na mesma medida, é preciso enfatizar também, como já relatamos anteriormente, quanto nos preocupam as situações que nos fizeram eleger como compreensão a (in)tensa simplificação totalizante, com viés de regulação, que marca as políticas de currículo e formação da atualidade.

Ao fazer essas escolhas, alguns eventos em termos de política de currículo ocorreramnos quanto aos modos de produção de fetiches e seus etnométodos. Por mais que, neste momento histórico da educação do nosso país estejamos mergulhados(as) nas políticas que têm a concepção de "Base Nacional Comum" como um fetiche, faz-se necessário ressaltar, ainda, que esse viés de simplificação totalizante já vem pontuando nossas políticas educacionais e formacionais em outros momentos.

Tomemos como um dos exemplos destacados o fetiche vinculado ao construtivismo piagetiano, com significativas ressonâncias nas pautas e práticas curriculares e de formação das instituições educacionais brasileiras. Além do psicologismo aí verificado, escolas e sistemas aderiram a essa epistemologia cognitiva como uma panaceia pedagógica. Ou seja, um milagre educacional que posteriormente transformar-se-ia numa espécie de epifania pedagógica em termos de política de currículo - vide os princípios que regem os Parâmetros Curriculares Nacionais -. Assim, como uma mercadoria extremamente atraente, 
principalmente para o sistema educacional privado, que, através de outras submetáforas pedagogicamente encantatórias - método ativo, educação construtivista, Escola Jean Piaget etc -, inundou o imaginário pedagógico-curricular, bem como o campo da formação de professores(as).

Em vários contextos educacionais a partir dos anos 1980, ou se era construtivista, ou não era possível estabelecer-se como competência pedagógica. Pesquisadores(as) do construtivismo piagetiano e educadores(as) que se autodenominavam construtivistas povoavam o Ministério da Educação e as Secretarias de Educação Estaduais e Municipais. Produzia-se assim, um fetiche ao modo da criação de um mito pedagógico. Alguns educadores(as) eram instados(as) a sentir-se constrangidos(as) em não concordar com algo que não fosse vinculado de alguma maneira a esse mito, que, em geral, atuava fincado na promessa de uma certa magia que apontava, ademais, para o sucesso moral, aprendente e profissional, na medida em que garantia inteligências eficientes para o mundo do trabalho, da produção e do exercício da cidadania. Intensificavam-se nesse contexto, as pautas e propostas de formação vinculadas ao trabalho e à formação docente.

Com dificuldades os modelos de avaliação tentavam adaptar-se a essa perspectiva epistemológica. Nesse cenário, as políticas de currículo e formação reforçavam esse fetiche e chegavam também às instituições educacionais e seus currículos, alimentando uma demanda que alcançava as universidades e seus cursos de licenciatura com significativa força heurística e formacional. Nesse contexto, o pedagógico-universitário tinha seus departamentos recheados de laboratórios e grupos de pesquisas mobilizados para pensar o construtivismo piagetiano no pedagógico, assim como mobilizavam de forma significativa publicações com esse tema. Em síntese, o construtivismo transformara-se, assim, num fetiche-panaceia.

Quando a crítica inaugura explicitações principalmente quanto ao etapismo piagetiano e seu inerente evolucionismo, ficaram publicamente argumentados como os conteúdos e métodos pedagógicos ditos construtivistas padeciam dessas dificuldades formacionais, no sentido da simplificação totalizante da sua apropriação pelo campo educacional, levando em conta, principalmente, as inerentes questões socioculturais que pautam de forma inarredável a educação como prática social.

Especificamente no que concerne às políticas de currículo os PCNs - Parâmetros Curriculares Nacionais (BRASIL, 1997), e a implementação dos Parâmetros em Ação (BRASIL, 1998) vão paradoxalmente parametrizar o construtivismo pedagógico para/nas escolas e suas disciplinas e por consequência as propostas de formação de professores(as). Assim, a política de currículo elege um fetiche a serviço da sua simplificação totalizante, que, aliás, tende sempre, nos nossos contextos educacionais a essencializar-se. Opta-se na política de currículo e formação pelo purismo teórico e metodológico, pela homogeneização identitária de uma epistemologia que pretende tornar-se pedagógica.

No contexto e no movimento desse gosto pelos fetiches-panaceia, num salto temporal para o que estamos vivendo hoje em termos de política de currículo, a partir de um claro processo de produção de identificações transingulares que vão atravessando as pautas das políticas educacionais entre nós, a fetichização nas/das denominadas políticas e suas 
consequências generativas tornam-se uma assombração para educadores(as) críticos(as) do instrumentalismo curricular e sua vontade de regulação: surge aqui o já criticado reino mágico das competências como uma concepção educacional e como um organizador curricular-formacional (PERRENOUD, 2000; FREITAS, 2002; RAMOS, 2002; TOMASI, 2004). A propósito, em outubro de 2016, numa entrevista concedida ao Programa Roda Viva, Perrenoud rebate o argumento realizado por uma das representantes da Secretaria de Educação Fundamental do MEC presentes na entrevista, ao afirmar o papel orientador das competências para toda e qualquer política educacional e de formação a ser efetivado no Brasil pelo Ministério. Com alguma veemência, Perrenoud responde que sua concepção de competências implicava numa visão globalizante e relacional de saberes, habilidades e valores, tomando como referência contextos educacionais concretos, assim como não fora pensada com o intuito de totalizar políticas educacionais. Esse autor complementa o seu argumento, explicitando que jamais as competências, na sua concepção, poderiam ser reduzidas a um conjunto de habilidades descoladas das questões complexas do mundo do trabalho, da diversidade e dos valores educacionais. Há que pontuar, entretanto, que em várias obras do autor citado, sobre as competências nos campos do currículo e da formação, incluindo a formação de professores(as), as competências como perspectiva educacional sofrem de uma clara inflexão deôntica (PERRENOUD, 2000; 2004).

Mesmo nesse contexto de argumentos, debates e críticas, a concepção de competências emerge como mais uma panaceia ampliada nas políticas de currículo e formação, porquanto intenciona abarcar todo o sistema educacional, criando para tal regulações que visam garantir respostas coerentes com essa perspectiva. Pautam, portanto, políticas curriculares e de formação, avaliação da aprendizagem, avaliações institucionais, formação inicial e continuada de professores(as), concepção e avaliação de cursos, concepção e estruturação de livros, materiais didáticos, etc. Deonticamente a fetichização da política de currículo se torna uma regulação sem explicitações solidárias nos seus documentos. Há que se ressaltar, porém, que os estudos do campo curricular têm desenvolvido e largamente disponibilizado para estudos e proposições curriculares mais de uma dezena de "modelos" de currículo com possibilidades de articulação formacional intercrítica entre eles, levando em conta a diversidade e a complexidade do saber escolar e seus contextos, bem como das aprendizagens educacionais e suas circunstâncias trabalhadas pelos(as) professores(as). Apesar dessa disponibilidade, o purismo identitário curricular se repete com uma significativa força estandardizada e homogeneizante.

Como forma de simplificação, percebe-se, ademais, como a apropriação das teorias que tratam de organizadores curriculares chegam de forma reduzida aos cenários educacionais e à formação de professores(as). Por exemplo, na BNCC (BRASIL, 2018a) e suas recomendações veiculadas pelo Programa ProBNCC - Programa de Apoio à Implementação da Base Nacional Comum Curricular (BRASIL, 2018b), assim como as diretrizes de formação da BNC-Formação (BRASIL, 2019), as competências são dissolvidas no instrumentalismo do desenvolvimento de habilidades. Faz-se necessário alertar que essa simplificação é o modo pelo qual as políticas de currículo e formação no Brasil construíram 
opção nas suas - havemos de convir - equivocadas apropriações das competências como princípio educacional e organização curricular e formacional.

Observa-se ainda não existir nessa perspectiva de política de currículo e formação de professores(as) quaisquer compromissos com as explicitações e os debates públicos no que se refere às escolhas vinculadas a princípios curriculares e formacionais, conceitos cultivados, orientações e recomendações. O fetiche que simplifica e totaliza se impõe, promete, regula e aponta para resultados esperados. Ademais, ao criar essencialismos identitários, tende ao discurso do purismo sociotécnico em termos de política de currículo e formação, visto que trabalha intensamente para produzir "idolatrias" como nos explicita Pinar (2014). De forma deôntica, como vimos realçando, aponta os métodos que levarão aos resultados prometidos pelos ditames da política. Como uma concepção funcionalista de currículo e de política de currículo e formação, perspectivam gestores(as), professores(as), coordenadores(as) e estudantes como se fossem "idiotas culturais" das questões curriculares e formacionais, porquanto despreza suas diversas e importantes experiências e conquistas nesses campos e seus entretecimentos. Inspirada na Etnometodologia de Garfinkel (1976), essa é uma crítica aguda realizada pela Teoria Etnoconstitutiva de Currículo (MACEDO, 2016), principalmente dirigida aos modos funcionalistas de se perceber a organização e a dinâmica curricular-formacional. Nesse horizonte, os diversos atores e atrizes curriculantes do mundo educacional, com atenção destacada aos(às) professores(as), seriam epifenômenos, ou seja, existem, mas não têm tanta importância para a funcionalidade da política curricular e suas propostas formacionais. Apontam, em geral, para a "aplicação", a "adaptação" e a "adequação" curricular. Com essa visão, as com-versações curriculantes restringem-se aos fetiches das propostas de grupos de governo. Aqui, o longevo ditame de se pensarfazer currículo e propor formação sem o outro se transfigura no modus operandi das políticas de currículo e formação dos tempos presentes.

Nos termos da fetichização que simplifica e totaliza, currículos e propostas formacionais por competências pretendem-se um fetiche-panaceia com ressonâncias excludentes, porquanto questões vinculadas à diferença e a diversidade estão, em geral, ausentes, não cabem, portanto, como pauta curricular e proposta formacional. Assim, em documentos como a Resolução CNE 02/2019, a denominada BNC-Formação, a concepção de formação de professores(as) é reduzida a dispositivos de mediação pedagógica. Instrumentalista, está longe de pensar tanto a formação docente vinculada às diversas dinâmicas do trabalho e da profissionalização, suas lutas e histórias de vida, quanto às dinâmicas propositivas das entidades que historicamente os/as representam. Ademais, formação no sentido amplo e plural, ou seja, como pauta sociotécnica, ontológica, epistemológica, ética, política, estética e cultural, como experiência irredutível, acontecimental e laboral, torna-se ausência. Encontra-se nesse movimento outro fetiche como simplificação totalizante, entretecido às pautas das políticas de currículos e formação atuais: a compreensão e o gosto pela avaliação como regulação intensificada e a produção de eficiência compreendida pelo viés dos interesses do capitalismo do século XXI. 
Essa questão merece uma compreensão atenta, faz-se necessário realçar, levando em conta os interesses históricos em fazer do currículo e da formação pautas e práticas reguladas pelos mercados e seus apelos fetichizantes de consumo.

\section{Por concluir}

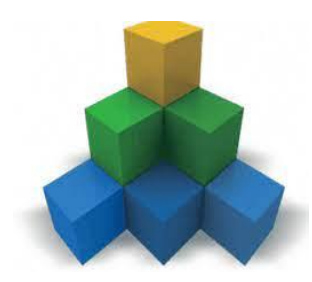

Figura 4: Logo da BNCC simbolizando o lema das políticas educacionais do MEC pautado no

"Direito ao Desenvolvimento e à Aprendizagem". Tenta-se de veicular como funciona a Base Nacional Comum Curricular com suas superposições de bases, em forma piramidal. Aprendizagem e formação são aqui representadas como acúmulos progressivos.

Disponível em: https://www.cranium.com.br/como-funciona-a-base-nacional-comumcurricular-bnccl. Acesso em agosto de 2021.

É comum ouvirmos em meio aos argumentos - em geral avessos à intercriticidade elucidativa e propositiva - que sustentam as atuais políticas de currículo e formação que "currículo é tudo que acontece e move a escola"; que "currículo por competências é a melhor opção política para orientar e compor práticas formacionais"; que "formação eficiente é a resultante de currículos bem adequados ou adaptados às competências requeridas pelas políticas de currículo tecnicamente elaboradas". Dificuldades de compreender o campo curricular-formacional, suas complexidades, suas especificidades e entretecimentos teóricopráticas? Talvez. Presença de ressonâncias da configuração de fetiches, pelas vias de políticas de sentido simplificadas e totalizantes? Essa é a preocupação fundante deste escrito.

A fortiori, essa possibilidade vislumbra-se para nós quando levamos em consideração a força das questões e pautas curriculares e formacionais no presente, notadamente vinculadas a segmentos políticos que estão à frente das políticas de currículo e formação de professores(as), seus interesses e suas orientações funcional-instrumentalistas. Esse é um cenário, entre outros, em que currículo e políticas de currículo e formação passaram a agregar poder aos diversos interesses socioculturais, tornando-se, assim, "território contestado" e "arenas de disputas" (SILVA, 1999b; MOREIRA e SILVA, 1995; ARROYO, 2011), porquanto, nesse contexto, emergem, por conseguinte, vinculados às relações com o saber como substantivo e como adjetivo, movimentos críticos-propositivos que se afirmam criticamente como diferença no cenário formacional, ao produzirem reexistências em rede, instituindo, assim, políticas afirmativas e reivindicatórias, na busca de diferenciações curriculares e formacionais em meio aos ditames deônticos das atuais políticas de currículo e formação. A exemplo, temos no momento as ações ampliadas de reexistência de 
movimentos educacionais e de entidades representativas de professores configuradas por lutas contra os retrocessos, as intenções políticas e a má qualidade da Resolução 02/2019 do CNE.

Em síntese, a partir das nossas inspirações e dos nossos argumentos curriculares e formacionais crítico-constitutivos, concluímos - nesse escrito - que o fetiche como uma metáfora curriculante é bom para reexistirmos e para transvermos cultural e intercriticamente, o movimento propositivo das atuais políticas de currículo e formação oficiais, assim como as estratégias dos diversos movimentos e ações que reexistem diante dessas políticas. Nas especificidades das nossas preocupações aqui descritas e discutidas, realçamos como fetiches são fundantes nas políticas analisadas, a partir da produção das simplificações totalizantes e ressonâncias que instituem. Aliás, ampla e (in)tensamente contestadas em função do viés político que adotam e ao qual aderem.

\section{Notas:}

1. Para Atlan (1993), na dinâmica intercritica, verifica-se uma construção crítica na qual o significativo é a passagem obrigatória pela relatividade da moral e da cultura, nos seus confrontos, que permitirá a existência de múltiplos "eus", cada um deles centro do mundo, ao mesmo tempo que reconhece no outro a sua irredutibilidade como único traço comum e, em verdade, universal. Na Teoria Etnoconstitutiva de Currículo a intercriticidade como objetivação de encaminhamentos curriculares e fomacionais nasce e realiza-se a partir de amplas e aprofundadas com-versações curriculantes (MACEDO, 2016).

2. A concepção de implicação questiona sempre o lugar, a experiência e a dinâmica do sujeito na relação com o saber. Ou seja, como processos existenciais, libidinais, morais, políticos, estéticos e culturais estão sempre presentes como modos de produção e mobilização de saberes (MACEDO, 2009). Vivendo zonas de elucidação e de opacidades, a implicação não pode ser confundida com engajamento, escolhas, por mais que possam estar entretecidos. Ademais, Guattari (1999, p. 23) nos diz que o sujeito implicado não pode contentar-se em interpretar. Ele é instado a lançar-se, inter-vir.

3. No sentido aqui trabalhado, simplificações acontecem em compreensões, explicações e proposições que, em geral, desvinculam dos seus diversos contextos ações e realizações, e, com isso, perdem suas vinculações e relações constitutivas (MORIN, 1992; MACEDO, 2016).

4. Compreensões e proposições totalizantes costumam tomar a parte por uma pretensa totalidade, assim, produzem e alimentam generalizações e abstracionismos, sem levar em consideração especificidades e singularidades das realidades e seus cotidianos, bem como suas emergências eminentemente plurais, singulares e singularizantes.

5. A concepção de analisador é tomada de empréstimo da compreensão da Análise Institucional Francesa. Trata-se de situações que, ao experienciarem disputas por significados - confrontos, conflitos e debates permitem a pluralidade de vozes e, a partir daí, compreensões pontuais e ampliadas de realidades. Pelas suas características, o analisador é (in)tensamente generativo (LOURAU, 2004).

6. A concepção de etnométodo foi cunhada por Garfinkel (1976), na configuração da sua teoria etnometodológica. Essa concepção nos diz que, para todos os fins práticos, interativamente e através de 
políticas de sentido culturalmente mediadas, constituímos formas, jeitos, maneiras de compreender ações e realizações, assim como produzimos "ordens sociais".

7. A indexicalização é compreendida pela etnometodologia como a vinculação cultural de toda e qualquer ação e suas realizações. Nos estudos e pesquisas pautados na etnometodologia, a indexicalização das ações é fundante para seu rigor heurístico.

\section{Referências}

ARROYO, Miguel. Currículo, territórios em disputa. Petrópolis: Vozes, 2011.

ATLAN, Henri. Com razão e sem ela. Intercrítica da ciência e do mito. Tradução de Fátima Gaspar e Carlos Gaspar. Lisboa: Instituto Piaget, 1993.

BENJAMIN, Walter. Charles Baudelaire. Um lírico no auge do capitalismo. São Paulo: Brasiliense, 1994.

BRASIL. Ministério da Educação. Secretaria de Educação Fundamental. Parâmetros Curriculares Nacionais - (PCNs). Brasília, 1997. Disponível em: http://portal.mec.gov.br/seb/arquivos/pdf/livro01.pdf. Acesso em: agosto, 2021.

BRASIL. Ministério da Educação. Secretaria de Educação Fundamental. Parâmetros em Ação. Brasília, 1998. Disponível em: http://portal.mec.gov.br/seb/arquivos/pdf/pcn_acao/pcnacao_fund1e2.pdf. Acesso em: agosto de 2021.

BRASIL. Ministério da Educação. Base Nacional Comum Curricular - (BNCC). Brasília, 2018a. Disponível em: http://basenacionalcomum.mec.gov.br/\#/site/inicio

BRASIL. Ministério da Educação. Programa de Apoio à Implementação da Base Nacional Comum Curricular (ProBNCC). Portaria n. 331, de 5 de abril de 2018. Brasília, 2018b. Disponível em: phpbJEN9S_5acba4bfbdff8.pdf. Acesso em: agosto de 2021.

BRASIL. Diretrizes Curriculares para Formação Inicial e Continuada em nível superior de Profissionais do Magistério para a Educação Básica - (BNC-Formação). Resolução CNE 02/2019. Brasília, 2019. Disponível em: http://portal.mec.gov.br/docman/dezembro-2019-pdf/135951-rcp002-19/file. Acesso em: agosto de 2021.

FREITAS, Luiz C. Neotecnicismo e formação do educador. In: Alves, Nilda. (Org.) Formação de professores: pensar e fazer. São Paulo: Cortez, 2002, p 89-102.

GARFINKEL, Harold. Studies in ethomethodologie. New Jersey: Prentice Hall, 1976.

GUATTARI, Felix. A transversalidade. In: Psicanálise e transversalidade: ensaios de análise institucional. Aparecida /S.P: Ideias \& Letras, 1999.

LOURAU, René. Objeto e Método da Análise Institucional. In: ALTOÉ, Sonia. René Lourau: Analista Institucional em Tempo Integral. São Paulo: Hucitec, 2004, p. 38-50.

MACEDO, Roberto S. Atos de currículo e autonomia pedagógica. Petrópolis: Vozes, 2013.

Currículo: campo, conceito e pesquisa. Petrópolis: Vozes, $7^{\mathrm{a}}$ Edição, $2^{\mathrm{a}}$ reimpressão, 2021.

Compreender e mediar a formação o fundante da educação. Brasília: Liber Livro, 2009. 2016.

MAQUIAVEL, Nicolau. O príncipe: texto integral. São Paulo: Edipro, 2018.

MOREIRA; Antônio Flávio; SILVA, Tomaz T. (Org.) O currículo e os novos mapas políticos e culturais. Petrópolis: Vozes, 1995.

MORIN, Edgar. Introduction à la pensée complexe. Communication et complexité. Paris: ESF Éditeur, 1992. 
PERRENOUD, Philippe. Dez novas competências para ensinar. Porto Alegre, Artmed, 2000.

Ciclos de aprendizagem: um caminho para combater o fracasso escolar. Tradução de Patrícia Reuillard. Porto Alegre: Artmed, 2004.

Entrevista concedida ao Programa Roda Viva. TV E São Paulo. Outubro de 2016. Em: https://www.youtube.com/watch?v=fcbuv6uWiO4

Acesso em agosto de 2021.

PINAR, William F. Quem é William Pinar? Entrevistas com Maria Luisa Süssekind. Petrópolis: DP et Alii, 2014.

RAMOS, Marise. Pedagogia das competências: autonomia ou adaptação? São Paulo: Cortez, 2002.

SILVA, Tomaz T. da. O Currículo como fetiche: a poética e a política do texto curricular. Belo Horizonte: Autêntica, 1999a.

Documentos de identidade: uma introdução à teoria crítica do currículo. Belo Horizonte: Autêntica, 1999b.

TOMASI, Antônio. Da competência à qualificação. Campinas: Papirus, 2004.

\section{Correspondência}

Roberto Sidnei Macedo: Licenciado em Psicologia e Psicólogo Clínico/Educacional pelo Centro Universitário de Brasília, Mestre em Educação pela Faculdade de Educação da Universidade Federal da Bahia, Doutor em Ciências da Educação pela Universidade de Paris Saint-Denis, com Pós-Doutorados em Currículo e Formação pelo Instituto de Psicologia e Ciências da Educação da Universidade de Fribourg-Suíça e pelo Instituto de Educação da Universidade do Minho-Portugal. É Professor Titular da FACED-UFBA, bem como é o atual Diretor desta instituição. Seus estudos, pesquisas e ações formacionais estão vinculados às questões e pautas curriculares entretecidas aos dispositivos e às experiências formativas. (fonte 10)

E-mail: rsmacedo@outlook.com

Texto publicado em Currículo sem Fronteiras com autorização dos autores. 